\title{
مقدمة العدد
}

\section{بقلم : رئيس التحرير}

بحمد الله وتوفيقه يقوم كاتب هذه السطور بكتابة مقدمة العدد الأول ، من المجلد الساد، من المجلة المصرية لعلم النفس الإكلينيكي والإرشادي، مما يدل على تراكم رصيد نجاحها للعام السادس على التوالي. ولكني بلغة التأمل meditation العلاجي الناتج عن خبرة التعقل mindfuleness أراني تعتريني مشاعر شديدة التناقض، أحد طرفيها الحالة التي يمثلها تقدم الجمعة المصرية للمعالجين النفسيين ، وتلبيتها لمعظم رغبات من يقومون بالعمل الاكلينيكي ويقدمون خدمات نفسية متخصصة في مصر والعالم العربي، وتحقيقها لمعظم أهدافها على الرغم من قصر عمرها، وبصفة خاصة ثلاثة مجالات، أولها : انتظام صدور هذه المجلة على الرغم من كونها تنشر بحوثا في تخصص دقيق هو علم النفس الإكلينيكي والإششادي، وثانيها : انتظام الدورات التدريبية والخدمية بشكل يدعو الى الدهشة على الرغم من شدة المنافسين في مصر المحروسة، وثالثها : انتظام انعقاد مؤتمر الحالة المصغر كبديل لمؤتمرات الحالة التى كانت تعقد شهريا بمستثفى العباسية على عهد أ.د. مصطقى سويف ثم توققت من دون إبداء أية أسباب، وكان يحضرها جل الاختصاصيين النفسيين العياديين الذين كانوا يعملون بوزارة الصحة المصرية، وكذلك خريجي الطب النفسي وطلاب الفرقة الرابعة وطلاب دبلوم علم النفس التطبيقي الاكلينيكي، وكانت الفائدة العلمية والمهنية غير عادية. أما الطرف الآخر الذي يصبغ مشاعرى بصبغة الحزن الى درجة البكاء، فيتمثل في حالة العنف والاقتتال الناتجة عن كل أثكال الانحراف الفكري، وهو عنف يجتاح كل العالم من أقصاه الى أقصاه بصفة عامة، وفي مصر وليبيا وسوريا واليمن والعراق بصفة خاصة،عنف دموي متعطش للقتل في كل اتجاه، حتى أن قرية الروضة بسيناء المقدة يقتل رجالها وشبابها ويافعيها وأطفالها في ساعة زمن وهم يصلون، وتفقد أسرة واحدة اثني عشر فردا من رجالها في لحظة واحدة، ولم يتبق منها سوى رية هذه الأسرة، سيدة من صبرها وجلاها فاقت خنساء عصر النبوة. درس كبير لمن يعتبر ويعرف الحال التى انتهينا إليها بسبب التصنيف العقائدي والأيديولوجي والقبلي والفكري العفن، درس وموعظة لأى حاكم سياسي يريد أن يعرف مسبقا نتيجة تبني البشر لمعتقات لا عقلانية ولأنماط بالية من الفكر والتفكير الثنائي المتصلب المتحجر العياني الدوجماطيقي، ومدى حاجة كل هولاء للعلاج الجلي السلوكي المعياري بكل مجالاته ومهاراته.

ويالطبع لكى أخرج من هذه الحالة شديدة التناقض والسخف، كان على أولا أن استخدم التفكير والحوار الجدلي بالإضافة الى التأمل المنبثق عن التعقل المتيقظ العميق، لحل هذا التناقض، فانتهيت إلى ضرورة تقبل ما حدث لكونه جزءا من عالمنا اليوم وحدث من أحداث العنف التى ابتليت بها البشرية والإنسانية في زمانتا هذا ، مع التشبث الثديد بوضع صيغة للقيام بالتغيير الإيجابي في طرق التفكير وفي آليات العمل والإنجاز. ويأتي على رأس آليات التغيير الإيجابي الوطنية، أن تجتمع إرادة الجميع ساسة وشعويا على إزالة كل السبل 
التي تثكل كل طرق الانحراف الفكري، لأنه أساس كل بلاء وغلاء، كما تستعين الدولة بأقسام العلوم الاجتماعية والنفسية والثرعية والفلسفية والمتخصصين فيها لاجتثاث هذا الفكر المنحرف المتطرف، ووضع خطة ذات جدول زمني محدد لإنتاج السلع الاستراتيجية ومستلزمات الإنتاج ليس وصولا فحسب لحد الاكتفاء الذاتي بل للتصدير كذلك، وخطة للنهوض بالتعليم والصحة وتنمية المناطق الأكثر فقرا، والأكثر عزلة وتخلفا حتى لا يرتع فيها هذا الانحراف الفكري بكل أثكاله، ونمنع كل أثكال التمييز والتزام العدالة منهجا للحياة، وأن يكون بناء مؤسسات الدولة الحديثة القوية في كل المجالات هو هدفنا، من دون أن تطفى مؤسسة على أخرى بلا مبرر، وأن توضع جداول زمنية أمام الحكومات والجامعات لإنجاز هذه الخطط جميعها بأيادي مصرية ، كل منهم في تخصصه، ومن يعجز عن الإسهام والإنجاز يختفي بالأمر من الساحة شريطة توفير كل أسباب الإنجاز والإسهام حتى لا يكون هناك مبرر أو مسوغا للكسل والتقاعس. وأملي قبل أن أموت أن تكون جميع الوظائف الحكومية والإدارية وفي كل دور العلم والتربية وفقا لعقود زمنية ومسابقات واختبارات دورية يخضع لها كل من يريد الاستمرار في وظيفته أو منصبه، ويكون أحد أبرز معايير الاستمرار في الوظيفة، أيا كانت ، هو الإنتاج والتظوير وفقا لمعايير الجودة، ومن يخفق يرحل لعمل آخر يمكنه أن ينجح فيه، حتى نستطيع التظلب على فوضى التعيين وقتل العدالة وإنتشار الفساد الإداري واعتبارات الحسيب النسيب وترك صاحب العلم والدراية والخبرة والإنجاز .

هذا هو الحل الذي اتبعته لكي أخرج من فوضى التناقض في مشاعري وانفعالاتي، ويكمن في تحمل الواقع المرير البغيض الذى نعيشه الآن بسبب الارهاب الناتج عن الانحراف الفكري، وما نتج ولا زال ينتج عنه كرب نفسي شديد، وذلك إلى حين ووقت أرجو ألا يطول، وأثناء تحملي لهذه الأقدار الثديدة من الكرب النفسي مؤقتا، أضع خططا تلائم ثقافتي واحتياجاتي للقيام بالتغيير الإيجابي في الواقع الذي أعيشه، ويعد ذلك من أعظم أساليب العلاج الجلي السلوكي ، الذي يقوم على مهارات حل التناقض ومهارات الصدق والمصداقية، ومهارات التأمل والتعقل اليقظ العميق، ومهارات تنظيم الأت والإنفعالات، ومهارات حل المشكلات بأسلوب تحليل السلاسل الزمنية وتحليل الروابط، ومهارات التأثير بين الشخصي، ومهارات تحمل الكرب النفسي بآليات تقبل الواقع المرير في الوقت الذي نلتزم فيه جميعا بالقيام بوضع خطط التغيير الإيجابي لهذا الواقع وتنفيذها خلال مدد زمنية محددة، ومهارات التقبل والالتزام التي تمنع الانتكاسة والعودة للوراء، ويظلف كل ذلك سياق وسياج اجتماعي ديني أخلاقي لضبط بوصلة التغيير والسيطرة عليها حتى لا تجنح مرة أخرى للانحراف الفكري وما ينجم عنه من ويلات.

على أية حال كنت أتمنى أن أبدأ مقدمة هذا العدد لاستقبال عام علمي مهني جديد، وحالنا لا يدعو لهذا القدر من الحزن والتنغيص،، ولكن قدر الله وماشاء فعل. وكالعادة يضم هذا العدد أربعة بحوث، لحسن الحظ ثلاثة منها بحوث في التذخل، ويحث رابع وأخير في الكثف عن دور العملية الوسيطة الناتجة عن الأفكار الآلية السلبية ودورها في تثكيل القلق النفسي والاكتئاب الأساسي وتثكيل سلوك التدخين كسلوك إدماني، 
وهذا النمط من البحوث نادراً جدا في الإنتاج الفكري النفسي.وتكشف مراجعة بحوث التدخل التي يضمها هذا العدد عن تقلم علمي ومهني غير مسبوق، لأن هذه البحوث أخذت في حسابها جميعا عند تصميم برامجها توفير مؤثرات معدلات الفعالية وإلكفاءة ومعدلات التأثير effectiveness ، التي من دونها لا نعرف أبدا استمرار معدلات التحسن والثفاء، ولا معدلات الانتكاسة، ومن ثم لا يمكن أن يتهم العلاج النفسي في زماننا هذا بأن نتائجه تعادل نسب الثفاء التلقائي، التي تحدث عنها عالمنا الكبير أيزينك في مقالاته في ستينيات القرن الماضي. كذلك نرى أن هذه البحوث أجريت على مرضى أمراض عصبية، كألم أسفل الظهر المزمن ( د. إيمان رمضان)، ومرضى اضطرابات سلوكية ذات أساس عصبي كاضطرابات المسلك لاى الأطفال ( د. نهى على عوض)، والإرشاد العقلاني الإنفعالي السلوكي لتحسين الوعى السياسي وأثره في الانتماء الوطني لاى الشباب الجامعي ( د. فاطمة بركات). كذلك فإن هذه البحوث الخاصة بالتدخل، مابين تلخل علاجي وتنموي، كلها التزمت بالمنهج والتصميم التجريبي البحت بقياس قبلي - بعدي متكرر مع فترات للمتابعة أضعاف فترات العلاج، الأمر الذي يعكس دقتها، وأن التدريب على كيفية إعداد برامج التخل بدأت تؤتي أكلها وثمارها. أما بحث الأفكار الآلية كعملية وسيطة ( د. هند ياسر عبد اللطيف) ، فأرى أن تطبيقاته - رغم أنه بحث يجسد دور التقدير النفسي الإكلينيكي وليس التذخل- في التخل العلاجي لا تخطئها العين، لأن دور المعتقات والأفكار الآلية السلبية حول التخين الكثيف دور خطير في تثكيل التحريض على التدخين أو التوقف عنه إذا أخذت هذه المعتقدات والأفكار الثكل الإيجابي الذي يدفع المدخنين للتوقف عن التذخين، ولذلك أثنارت النتائج الى التأثير المباشر وغير المباشر لهذه الأفكار الآلية السلبية في تثكيل المعاناة من القلق النفسي والاكتئاب المرتبطين بالتتخين، كما استطاعت التنبؤ بقوة بالتدخين المكثف.

وفي نهاية المقدمة، نرجو أن يفيذ من هذه البحوث جل المتخصصين في العمل الإكلينيكي والإرثادي والمثقف الجاد. والله من وراء القصد.

$$
\text { أ.د. محمد نجبب الصبوة }
$$

أستاذ علم النفس الإكلينيكي بجامعة القاهرة 